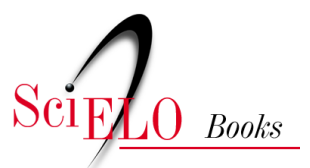

ed

\title{
Periferização da produção imobiliária no século XXI: a produção do Programa Minha Casa Minha Vida em João Pessoa - PB
}

\author{
Eliane Campos dos Santos \\ Paula Dieb Martins
}

\section{SciELO Books / SciELO Livros / SciELO Libros}

SANTOS, E. C., and MARTINS, P. D. Periferização da produção imobiliária no século XXI: a produção do Programa Minha Casa Minha Vida em João Pessoa PB. In.: MAIA, D. S., and MARAFON, G. J., eds. O programa Minha Casa Minha Vida: habitação e produção do espaço urbano em diferentes escalas e perspectivas [online]. Rio de Janeiro: EDUERJ, 2020, pp. 169-187. ISBN: 978-6500-03029-7. https://doi.org/10.7476/9786500030297.0007.

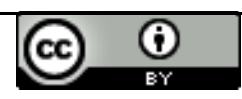

All the contents of this work, except where otherwise noted, is licensed under a Creative Commons Attribution 4.0 International license.

Todo o conteúdo deste trabalho, exceto quando houver ressalva, é publicado sob a licença Creative Commons Atribição 4.0.

Todo el contenido de esta obra, excepto donde se indique lo contrario, está bajo licencia de la licencia Creative Commons Reconocimento 4.0. 


\section{Periferização da produção imobiliária no século XXI: a produção do Programa Minha Casa Minha Vida em Joáo Pessoa - PB}

Eliane Campos dos Santos Paula Dieb Martins

\section{Introdução}

A cidade de João Pessoa, localizada no Nordeste brasileiro, tem apresentado intensas transformaçóes em seu espaço urbano no início do século XXI, tanto em decorrência da execuçáo de projetos urbanos realizados pelo poder público, quanto pela grande quantidade de lançamentos imobiliários empreendidos pelos agentes privados, predominantemente, de origem e atuação local.

De acordo com o estudo das Regióes de Influência das Cidades (REGIC) (IBGE, 2007), que definiu configuraçóes da rede urbana brasileira, João Pessoa é classificada como uma Capital Regional A, isto é, um centro urbano com capacidade de gestáo inferior à metrópole, com uma área de influência regional. A capital do estado da Paraíba apresenta uma população estimada de aproximadamente 811.000 habitantes (IBGE, 2017), ocupando uma área de $211,5 \mathrm{~km}^{2}$.

A partir de meados do século XX, a cidade sofreu um acelerado processo de expansão urbana, relacionado, sobretudo, à política de atuação do Sistema Financeiro de Habitação (SFH) por meio do Banco Nacional de Habitação (BNH) que, com o lançamento de conjuntos habitacionais, criou e consolidou a tendência de crescimento da cidade voltada para as direçóes Sul e Sudeste (Lavieri e Lavieri, 1999). Essa, por sua vez, resultou na produção 
da cidade espraiada (Santos, 2008), assim como no aumento das distâncias sociais no espaço intraurbano e no fenômeno de segregação - residencial (Villaça, 2001 e Corrêa, 2003) e/ou espacial imposta (Souza, 2003) -, cuja configuração persiste no espaço intraurbano de João Pessoa até os dias atuais.

O setor imobiliário de João Pessoa tem apresentado altos percentuais de crescimento, que por vezes superam aqueles referentes a outras cidades brasileiras. Tal foi o caso do aumento do número de estabelecimentos de atividades imobiliárias e de construção nela atuantes entre 2006 e 2015. Além disso, destacou-se também o crescimento do valor total gasto em construção e incorporação no Estado da Paraíba que, de acordo com dados da Câmara Brasileira da Indústria da Construção, entre 2005 e 2015, apresentou crescimento duas vezes maior que a média nacional.

Essas mudanças estão diretamente relacionadas a um contexto mais amplo provocado pela maior articulação do capital financeiro com o imobiliário e pela expansão do capital imobiliário que, no Brasil, ocorreu sobretudo a partir da década de 2000 , com a criação de uma conjuntura internacional e nacional (Melazzo, 2013).

Dentre as açóes que compóem tal conjuntura, destacam-se a mudança da lei de alienaçóes fiduciárias, o aumento dos subsídios pelos Fundo de Garantia por Tempo de Serviço (FGTS), a ampliação dos recursos do Orçamento Geral da União (OGU), a ampliação de crédito para a produção imobiliária, a abertura do capital imobiliário na Bolsa de Valores, a entrada de capitais internacionais no mercado imobiliário nacional e a criaçáo do Programa Minha Casa Minha Vida (PMCMV).

Nesse amplo contexto, como afirmou Melazzo (2013), “[...] o mercado imobiliário é considerado, portanto, como o lugar econômico da valorização de capitais que agem sobre a cidade e seus objetos na busca permanente e crescente de sua valorização" (p. 34). Sendo assim, para se compreender a produção do espaço urbano no Brasil contemporâneo, se faz necessária a articulação de escalas e processos, investigando os agentes, estratégias e projetos relacionados ao setor imobiliário.

Deste modo, diante das recentes e intensas mudanças no espaço urbano de Joáo Pessoa e do relevante aumento da produçáo imobiliária na cidade, o presente artigo tem como objetivo analisar a produçáo do seu espaço intraurbano a partir do PMCMV, no período compreendido entre os anos 2009 e 2018. Para tanto, foi realizada a caracterização da produção habita- 
cional do mencionado programa na cidade estudada e a identificação de suas repercussões no tecido urbano do município.

A pesquisa foi realizada em três etapas. A primeira, compreendeu o levantamento e a leitura de produção bibliográfica acerca dos assuntos ora abordados - tais como Rolnik (2015), Shimbo (2010), Maricato (2014), Rufino (2016), entre outros -, assim como do objeto empírico de estudo Lavieri e Lavieri (1999), Maia (2000 e 2014) e Martins (2019).

Em seguida, foi feito o levantamento em base de dados disponibilizada pelo extinto Ministério das Cidades, cujas informaçóes abrangem as unidades habitacionais contratadas, concluídas e entregues pelo PMCMV entre os anos de 2009 e 2018. Nela, foram coletados os quantitativos relativos às unidades habitacionais entregues e seus respectivos endereços. Com isso, foi possível quantificar a produçáo imobiliária do referido programa de acordo com cada faixa de renda, assim como visualizar sua localização no tecido urbano de Joáo Pessoa. Tais dados obtidos foram sistematizados e representados por meio de tabelas e mapas.

Por fim, a partir dos dados obtidos e sistematizados nas pesquisas bibliográficas e documental, foi desenvolvida uma análise geral sobre a produção do PMCMV em João Pessoa e a sua relaçáo como o processo de expansáo urbana da cidade. Como resultado, pode-se afirmar que, em João Pessoa, o PMCMV possibilitou a extensão do imobiliário e do urbano ao mesmo tempo que reforçou a segregação socioespacial ao implantar os empreendimentos de faixa mais baixa em áreas periféricas, nas bordas da cidade.

A análise é apresentada, a seguir, em duas partes: na primeira, são realizadas breves notas acerca da estruturação do espaço intraurbano de João Pessoa para fundamentar a análise mais específica da produção habitacional vinculada ao PMCMV na cidade entre 2009 e 2018, a qual é realizada em seguida, na segunda parte do capítulo. Por fim, são expostas as principais constataçóes e reflexóes da pesquisa.

\section{A estruturação da cidade no século XX: espraiamento e periferização em João Pessoa-PB}

De uma maneira geral, a estrutura urbana é uma realidade do espaço em um momento no tempo, que mostra como o espaço da cidade está organizado. Como bem descreveu Sposito (2004, p. 311), "a expressão 'estrutura 
urbana' é, a nosso ver, apropriada para se fazer referência à forma como se encontram dispostos e se articulam os usos de solo, num dado momento do contínuo processo de estruturaçáo dos espaços da cidade”.

De acordo com Villaça (2001), o espaço intraurbano estrutura-se de acordo com as condiçóes de deslocamento dos seus habitantes - tanto como força de trabalho quanto como consumidores -, os quais definem percursos marcados por práticas sociais e cotidianas que seguem tendências, indicaçóes e resultados. Desta maneira, essa estruturação passa a adquirir uma forma e uma lógica evolutiva específicas, a partir da luta de classes na produção de localizaçóes estratégicas nesse espaço. Afirma-se assim que a estruturação da cidade é orientada pela divisão técnica e social do trabalho.

A cidade de João Pessoa, fundada no século XVI, teve seu tecido urbano pouco alterado ao longo dos seus primeiros séculos de existência. Até o final do século XIX, permaneceu concentrada no entorno das suas unidades morfológicas originais, apresentando uma malha contínua, expandindo-se lentamente. Contudo, a partir de meados do século XX, tal processo tem sua intensidade e configuração modificada por meio, sobretudo, da atuação do Estado, tanto pela realização de obras e programas, quanto pela elaboração de leis de zoneamento, uso e ocupação do solo urbano.

Assim como ocorreu em outras cidades brasileiras, o tecido urbano de João Pessoa expandiu-se de forma mais latente e descontínua a partir da segunda metade do século XX, devido, principalmente, à atuaçáo da política habitacional com a construção de conjuntos habitacionais pelo Banco Nacional de Habitação (BNH) (Maia, 2000). Em tal período, diversos acontecimentos - como o aumento do uso do automóvel, as melhorias nos sistemas de transporte, o acelerado crescimento da populaçáo urbana -, bem como a intervenção do Estado no planejamento urbano desencadeou a expansão da malha urbana, fomentando agentes privados e intensificando as lógicas especulativas - fundiária e imobiliária - e a segregação socioespacial.

A habitação de interesse social no Brasil está associada à produção desigual do espaço urbano, sendo os déficits relativos à moradia um problema latente em nossa sociedade. Podemos observar ao longo da história da política habitacional diferentes formas de acesso à moradia, as quais se desenvolveram sob a lógica capitalista de produção.

O período anterior aos anos 1930 aponta inexpressiva presença do Estado no que diz respeito à produção da habitação. O princípio da intervenção 
estatal na questão da habitação de interesse social no Brasil teve início com destaque para o período Vargas (1930-54) com a criação dos Institutos de Aposentadoria e Pensão (IAPs) e da Fundação Casa Popular. Porém, a grande intervenção estatal na história da política habitacional brasileira no século XX foi, sem dúvida, a criação do Banco Nacional de Habitação (BNH) pela Lei n. ${ }^{\circ}$ 4.380, de 21 de agosto de 1964, que durou até 1986.

De acordo com Rufino (2016), durante o período, a produção imobiliária de mercado deu-se nas áreas centrais e privilegiadas da cidade e construiu edificaçóes voltadas para um público consumidor de alta renda. Deste modo, houve a valorização daquelas áreas, o que provocou a intensificação dos contrastes entre o centro e a periferia urbana.

Diante do acelerado aumento populacional, restou aos grupos com menores rendimentos, a ocupação de áreas menos valorizadas da cidade e distantes do centro, produzindo assim a "periferia dos pobres" por meio da espoliação urbana (Kowarick, 1979). Como descreveu Maia (2014),

Na história da urbanização brasileira, a expansão das cidades é marcada pelos grandes loteamentos oficiais destinados às camadas da populaçáo de maiores rendimentos e, também, pelos loteamentos irregulares ou clandestinos. Além disso, há a periferização da cidade produzida pelo Estado, com a construção de conjuntos habitacionais, destacadamente no período 1960-1980, financiados pelo Banco Nacional de Habitação (BNH) (p. 92).

O processo de periferização brasileira e as suas respectivas especificidades foi estudado e caracterizado por diversos autores das ciências sociais nas últimas décadas do século XX, tais como Francisco de Oliveira (1979), Lúcio Kowarick (1979), Bolaffi (1979) e Santos (2008). Sua origem está relacionada profundamente à atuação do Estado para promover um pacto político desenvolvimentista, com base na acumulação marcada por um padrão expansionista do urbano e da produção industrial.

Nesse momento de mudanças na base econômica com a ascensão e domínio da indústria, a população de João Pessoa apresentou inédito crescimento populacional decorrente, entre outros fatores, da migração da população que vivia da produçáo agrícola oriunda de regióes interioranas do estado em busca de melhores condiçóes de vida na capital. De acordo com os dados quantitativos referentes à população residente em João Pessoa de 1950 
a 2010 (tabela 1), observa-se que, além do relevante aumento apresentado, na década de 1950, a população de João Pessoa já se caracterizava como predominantemente urbana.

Tabela 1 - População residente no município de João Pessoa (1950-2010)

\begin{tabular}{l|l|l|l|l|l|l}
\hline \multirow{2}{*}{ ANO } & \multicolumn{3}{|l}{ URBANA } & \multicolumn{2}{l}{ RURAL } & \multicolumn{3}{l}{ TOTAL } \\
\cline { 2 - 7 } & TOTAL & $\%$ & TOTAL & $\%$ & TOTAL & $\%$ \\
\hline $\mathbf{1 9 5 0}$ & 89.517 & 93,29 & 6.436 & 6,71 & 95.953 & 100 \\
\hline $\mathbf{1 9 6 0}$ & 135.820 & 95,03 & 7.096 & 4,97 & 142.916 & 100 \\
\hline $\mathbf{1 9 7 0}$ & 213.569 & 96,40 & 7.977 & 3,60 & 221.546 & 100 \\
\hline $\mathbf{1 9 8 0}$ & 326.582 & 98,98 & 3.360 & 1,02 & 329.942 & 100 \\
\hline $\mathbf{1 9 9 1}$ & 497.600 & 100 & -- & -- & 497.600 & 100 \\
\hline $\mathbf{2 0 0 0}$ & 597.934 & 100 & -- & -- & 597.934 & 100 \\
\hline $\mathbf{2 0 1 0}$ & 720.785 & 99,5 & 2.730 & 0,5 & 723.515 & 100 \\
\hline
\end{tabular}

Fonte: IBGE - Censos 1970, 1980, 1991, 2000 e 2010; Plano de Desenvolvimento Urbano e Comunitário de João Pessoa - 1983-86 (PMJP, 1983). Elaboração da autora (2018).

Entre as décadas de 1960 e 1980, a produção dos conjuntos habitacionais do BNH em João Pessoa provocou uma expansão urbana em escala expressiva, numa área que era, até então, ocupada por estabelecimentos agropecuários, correspondendo assim à materialização da expressão já conhecida de que "a cidade vai engolindo o campo". Ao analisar a localização dos conjuntos habitacionais no território de João Pessoa, produzidos em período anterior e durante a atuação do $\mathrm{BNH}$, é possível constatar o que foi afirmado acima no tocante ao início do processo de periferização da cidade. ${ }^{11}$

Durante a atuação do BNH, de 1964 a 1986, foram construídas cerca de 29.000 unidades habitacionais em João Pessoa, distribuídas em 42 conjuntos habitacionais. Isso representou uma relevante produção imobiliária na cidade, tendo em vista que, de acordo com o Censo Demográfico do IBGE de 1970, havia apenas 38.663 domicílios permanentes em João Pessoa.

${ }^{1}$ Embora a maioria dos conjuntos do $\mathrm{BNH}$ tenha sido instalada em áreas periféricas, alguns deles foram implantados em áreas desocupadas contíguas ao tecido urbano existente de João Pessoa. Tais conjuntos foram aqueles implantados nos primeiros anos de atuação da instituição. 
Por se caracterizarem, predominantemente, como conjuntos habitacionais de grande porte - com centenas de habitaçôes -, foram, portanto, implantados em grandes lotes ou glebas disponíveis em áreas menos valorizadas, com solo mais barato, isto é, em áreas de expansão e/ou antigas propriedades rurais.

Essa ampla escala de produção, que se caracterizou por conjuntos habitacionais compostos por residências unifamiliares ocupando grandes extensôes de terra, contribuíram para a alteração das áreas limítrofes do perímetro urbano incorporando inclusive grandes glebas rurais, de modo que, entre os anos de 1972 e 1983, de acordo com Oliveira (2006), a área da cidade dobrou de tamanho. As terras rurais foram transformadas em urbanas, pois passaram a ser providas com os serviços e equipamentos de uso coletivo.

Vale ressaltar ainda que, nas décadas de 1960 e 1970, por meio de açóes do programa nacional de desenvolvimento e crescimento urbano, outras relevantes alteraçōes no entorno da malha urbana de João Pessoa influíram diretamente em sua estruturação. Foram elas: a implantação do Campus da Universidade Federal da Paraíba e do Distrito Industrial, na Zona Sul de seu território; e a criação de um anel rodoviário (BR-101/ BR-230) que corta o espaço intraurbano da cidade, ligando-o aos municípios vizinhos (Bayeux, Santa Rita e Cabedelo).

Deste modo, é possível afirmar que o programa nacional de desenvolvimento e dinamizaçáo da economia atuou diretamente na produçáo do espaço urbano local e, de fato, transformou a cidade "tradicional" de outrora, em cidade "modernizada", caracterizada pela expansão territorial e desconcentraçáo do seu centro tradicional, pelo surgimento de novas centralidades e pela diversificação de atividades e interesses sociais (Maia, 2000).

Nesse momento, novas tendências de crescimento de seu território foram estabelecidas, apresentando visivelmente a estratificaçáo do uso do espaço da cidade, marcado pelo aumento das distâncias sociais: na direção leste e norte se concentraram a populaçáo de alta renda e, para a direçáo sul e sudeste, foram conduzidas as de baixa renda (Lavieri e Lavieri, 1999).

Segundo Martins (2019), tal quadro de segregaçáo socioespacial e periferização urbana, conformado desde a década de 1960, se intensificou ao longo dos anos não apenas pela continuidade das dinâmicas que lhes deram origem, mas também em decorrência da criaçáo de marcos legais que os institucionalizaram e os nortearam, tais como o Código de Obras, o Código de Urbanismo e o Plano Diretor de João Pessoa. Deste modo, 
verifica-se assim que, ao longo do tempo, no tocante à legislação vinculada ao planejamento e controle do uso e ocupação do solo da cidade, foi realizada uma definição cada vez mais precisa das zonas destinadas à preservação ambiental e patrimonial, no entanto, constatou-se ao mesmo tempo a ampliação e a intensificação da ocupação da área urbana de modo descontínuo, assim como o seu avanço sobre a Área Rural (Martins, 2019, p. 102).

Assim, o espaço foi preparado para o mercado imobiliário pelo planejamento urbano, que estimulou o processo especulativo na cidade ao expandir o perímetro urbano e instalar infraestrutura urbana de forma desigual nas áreas da cidade (Santos, 2008).

De acordo com Santos (2015), na década de 1990, mudanças na política, no modo de organização e nos parâmetros de acumulação do capital acarretaram a centralização da dinâmica geográfica do capital e a sua concentração no espaço, de modo que houve a valorização das áreas centrais das grandes cidades em detrimento das suas zonas periféricas. Dessa forma, o padrão de ampliação do capital vinculado à expansão geográfica da cidade foi modificado a partir da década de 1980, com a crise do pacto desenvolvimentista do governo.

Nesse processo, o mercado imobiliário se destacou ainda mais como local de absorção dos excedentes com geração de lucro, substituindo as estratégias anteriores voltadas para o desenvolvimento econômico extensivo. No Brasil, as décadas de 1980 e 1990 foram marcadas, sobretudo, pela diminuição dos financiamentos habitacionais e pelo aumento dos índices de desemprego e do empobrecimento da população (Santos, 2015).

Nesse período, a política de habitação nacional sofreu intensa modificação: no lugar de uma "Política de Estado", na qual se insere a atuação do BNH, deu-se início uma "Política de Governo", que se caracterizou pela ausência de uma política definida e objetiva e pela presença de programas diversos e específicos, desenvolvidos segundo cada mandato presidencial, descentralizadas e distribuídas entre instituiçôes diversas, como a Caixa Econômica Federal (CEF) e o Banco Central (Bonates, 2007).

De acordo com Bonates (2007), nas últimas décadas do século XX e na primeira do século XXI, a produção estatal da habitação social em João Pessoa sofreu um arrefecimento em relação ao período de atuação do BNH. Entre 
1987 e 2006, foram financiadas pelo poder público cerca de 17.500 unidades habitacionais, implantadas predominantemente em bairros da Zona Sul da cidade. Os empreendimentos englobaram tanto habitações unifamiliares como multifamiliares (edifícios com quatro pavimentos, em média). A verticalização das construções deu-se devido às dimensões mais reduzidas e aos altos preços dos terrenos, e foi utilizada, também, como solução para melhor aproveitamento da área passível de construção do lote, para racionamento dos materiais, da mão de obra e dos custos.

Ademais, destacou-se também, em tal período, a produção habitacional realizada por empresas privadas - como cooperativas habitacionais e incorporadoras - por meio de financiamento pela CEF com recursos de programas habitacionais do governo. Tal produção, diferentemente daquela realizada pelo poder público, voltou-se para um público diversificado, geralmente com rendimento médio, e compreendeu um total de 4.536 unidades habitacionais localizadas, predominantemente, em áreas centrais e valorizadas da cidade (Bonates, 2007) (mapa 1). Assim, como constatou Martins (2019),

a produção de habitaçáo social em Joáo Pessoa, em tal momento, ocupou espaços já urbanizados da cidade e, portanto, não induziu dinâmicas de expansão e dispersáo urbana. Ademais, a implantação dos empreendimentos em bairros urbanizados não alterou a estruturação da cidade, formada no período de atuação do BNH. Pode-se então inferir que a construção dos conjuntos habitacionais no período em questão apenas intensificou a ocupação de bairros iniciada décadas antes, ao implantá-los em terrenos vazios remanescentes (p. 104-105). 
Mapa 1 - Localização dos conjuntos habitacionais produzidos no século XX em João Pessoa

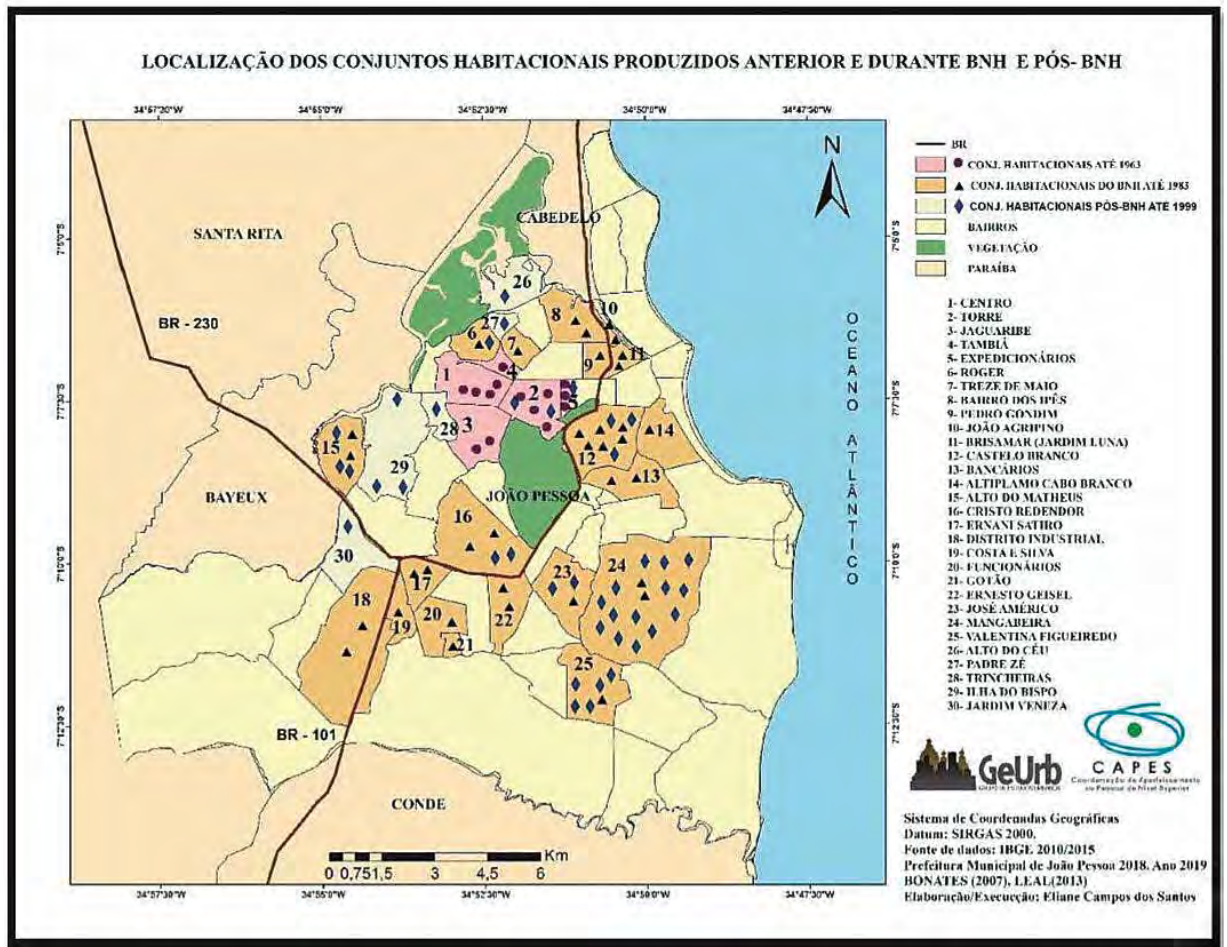

Elaboração: Eliane Campos dos Santos, 2019.

Conclui-se, portanto, que o Estado desempenhou papel preponderante na estruturação do território de João Pessoa, sobretudo ao longo do século XX e início do século XXI, tanto por meio das políticas públicas de desenvolvimento - entendido como crescimento -, quanto pela regulação do uso e ocupaçáo do solo, produzindo um tecido urbano expandido de forma espraiada e descontínua a partir do processo de periferização (Martins, 2019). Processo que, de acordo com Sierra (2004), assume no século XXI uma complexidade inédita, marcada por porosidades e ausência de limites precisos. 


\section{A periferia no centro da produção imobiliária: O PMCMV em João Pessoa-PB}

Após um período de ausência de políticas habitacionais no século XXI, deu-se início a um novo momento de estímulo à produção imobiliária no país, resultante do processo de neoliberalização da política e de recentes mudanças econômicas que - como mencionado na introduçáo - aproximaram cada vez mais o capital financeiro do setor imobiliário. Tais mudanças imprimiram novas dinâmicas urbanas no tecido da cidade, alterando profundamente a sua estruturação, sobretudo por meio da formação de novos conteúdos socioespaciais na periferia urbana.

Dentre as açôes do Estado que repercutiram na produção habitacional das periferias e na estrutura de muitas cidades brasileiras, destacam-se a implantação do Sistema Nacional de Habitação de Interesse Social (SNHIS) e do Fundo Nacional de Habitação de Interesse Social (FNHIS), a regulamentação do Estatuto da Cidade, a criação do Ministério das Cidades em 2003 e o início do Programa de Aceleração do Crescimento (PAC) em 2007.

Na primeira década do século XXI, houve a elaboração de uma agenda marcada pela construçáo de um Estado de direitos e, ao mesmo tempo, por pautas e práticas neoliberais. Foram realizadas açóes a fim de expandir o mercado interno, com a inclusão de estratos de renda mais baixa ao circuito de consumo. Os bancos e fundos públicos também retomaram seu papel a partir de programas como o PAC e o PMCMV, por meio da provisão de créditos e do estímulo aos investimentos tanto por parte do setor público como do privado (Rolnik, 2015).

No PMCMV, os preços dos imóveis são pré-determinados de acordo com cada faixa de renda contemplada, o que fez com que as empresas que produziam imóveis voltados para a comercialização através do programa utilizassem estratégias para minimizar os custos dos empreendimentos imobiliários e, assim, otimizar seus ganhos.

Dentre as estratégias, Rufino (2016) destacou a padronização, a ampliação da escala da produção e a escolha por terrenos mais baratos, geralmente localizados em áreas mais distantes dos centros das cidades. A ocupação das áreas mais afastadas se tornou ainda mais latente devido ao fato do PMCMV ter permitido o lançamento de empreendimentos nos municípios menores inseridos em regióes metropolitanas o que, por sua vez, "legitimou 
a metropolização do déficit” (p. 227). A ampliação das possibilidades e distâncias de localização dos empreendimentos fez com que, até 2011, a maioria das unidades contratadas pelo programa fossem inseridas em municípios localizados na periferia metropolitana (Rufino, 2016).

Contudo, na Regiāo Metropolitana de João Pessoa (RMJP), como constatou Martins (2019), a produçáo do PMCMV se localizou e se concentrou de modo diferente da realidade retratada por Rufino (2016). Ao analisar a quantidade de empreendimentos entregues pelo programa nas cidades que compóem a RMJP (tabela 2), foi possível constatar que as unidades habitacionais construídas no âmbito do mencionado programa se concentraram no espaço intraurbano de João Pessoa, principalmente aquelas inseridas na Faixa 1 que, segundo Rufino (2016), são as que geralmente estão localizadas nas áreas mais distantes dos centros urbanos.

Tabela 2 - Unidades entregues pelo PMCMV nas cidades que compóe a RMJP

\begin{tabular}{l|c|c|c}
\hline \multirow{2}{*}{ Cidades da RMJP } & \multicolumn{3}{|c}{ Unidades Habitacionais Entregues do PMCMV } \\
\cline { 2 - 4 } & Faixa 1 & Faixa 2 & Faixa 3 \\
\hline Alhandra & -- & 489 & 3 \\
\hline Bayeux & -- & 1.091 & 25 \\
\hline Caaporá & 30 & 15 & 2 \\
\hline Cabedelo & -- & 417 & 99 \\
\hline Conde & 219 & 398 & 23 \\
\hline Cruz do Espírito & -- & 1 & -- \\
\hline Santo & 6.622 & 34.633 & 1.935 \\
\hline Joáo Pessoa & -- & 102 & 6 \\
\hline Lucena & 123 & 471 & 21 \\
\hline Pedras de Fogo & 70 & 9 & -- \\
\hline Pitimbu & 43 & 85 & 5 \\
\hline Rio Tinto & 1.051 & 9.338 & 61 \\
\hline Santa Rita & & & \\
\hline
\end{tabular}

Fonte: Banco de Dados do Ministério das Cidades. Edição nossa (2018) 
Entretanto, não se pode afirmar que os mencionados empreendimentos foram implantados em áreas privilegiadas do ponto de vista da localização intraurbana. Ao identificar a localização da implantação de cada empreendimento do Faixa 1, observou-se que concentraram-se, sobretudo, em bairros periféricos da cidade, distantes do seu centro principal, aqui entendido como a área da cidade que ainda concentra os principais serviços, comércios e instituiçóes da cidade, apesar da coexistência de subcentros ou novas centralidades em seu espaço intraurbano (mapa 2).

Mapa 2 - Mapa de localização dos conjuntos habitacionais do PMCMV no município de João Pessoa - PB

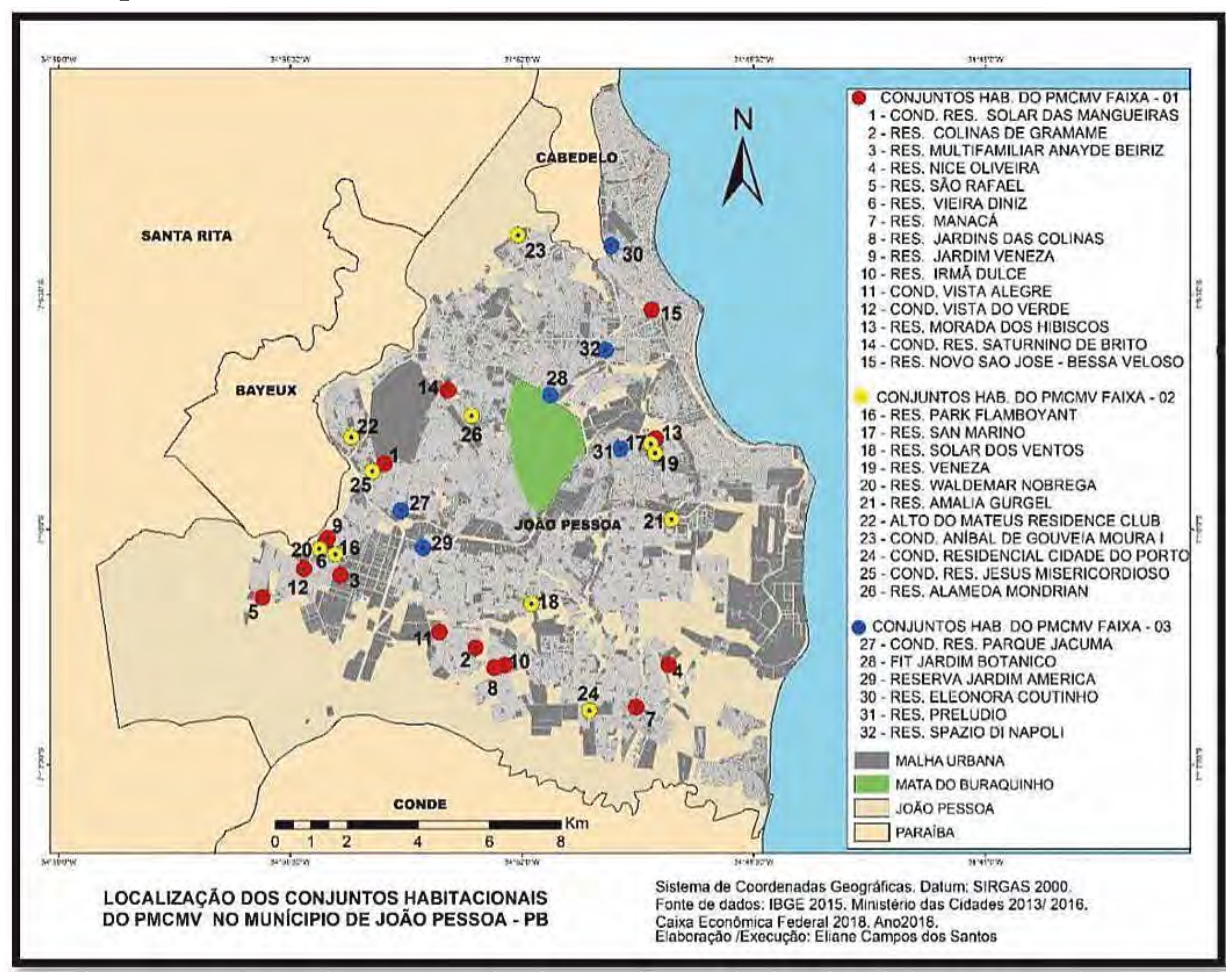

Elaboração: Eliane Campos dos Santos, 2018.

Apesar disso, não se pode afirmar que os empreendimentos do PMCMV estimularam um processo de dispersão urbana em Joáo Pessoa, tendo em vista que os eles ocuparam alguns vazios urbanos remanescentes, mas há continuidade no espraiamento, pois as construçóes se deram sobretu- 
do em áreas contínuas ao tecido urbano existente inseridas em zonas ou em bairros de ocupação recente, com relevante quantidade de lotes desocupados a serem comercializados.

Deste modo, com a ocupação desses novos espaços, houve acelerado processo de expansão urbana sobre áreas rurais remanescentes nas bordas do município e de sua valorizaçáo, pois, ao receberem infraestruturas e serem ocupadas, se transformaram em áreas urbanas.

As açóes das empresas construtoras e incorporadoras refletem nas transformaçóes do espaço e, principalmente, no espaço intraurbano, como está ocorrendo na periferia da cidade de João Pessoa, mas essas mudanças também ocorrem em outros setores, em áreas residenciais de grande valor especulativo. Contudo, na maioria dos casos, tais localizaçóes se devem a obras atreladas a projetos mais amplos de infraestruturação de comunidades/favelas ou à produção de mercado do PMCMV, voltada para as faixas 2 e 3 .

Os empreendimentos referentes às Faixas 2 e, principalmente, 3 do PMCMV foram implantados em áreas menos periféricas, com infraestrutura urbana mais completa e ocupação urbana consolidada. É possível identificar no Mapa 2, a localização de empreendimentos do PMCMV Faixa 3 em bairros como Torre, Tambauzinho, Aeroclube e Jardim Cidade Universitária.

Além da localização, os empreendimentos das três faixas diferiram também em relação às suas características estéticas, estruturais e funcionais. Aqueles vinculados à Faixa 1 apresentaram, geralmente, uma estrutura mais simples, com alvenaria estrutural, unidades com área privativa mínima exigida pelo programa e pela legislaçáo municipal, assim como reduzidas áreas de uso comum (foto 1). 
Foto 1 - Empreendimento PMCMV Faixa 1 (Res. Vieira Diniz), localizado no bairro Jardim Veneza, em João Pessoa - PB

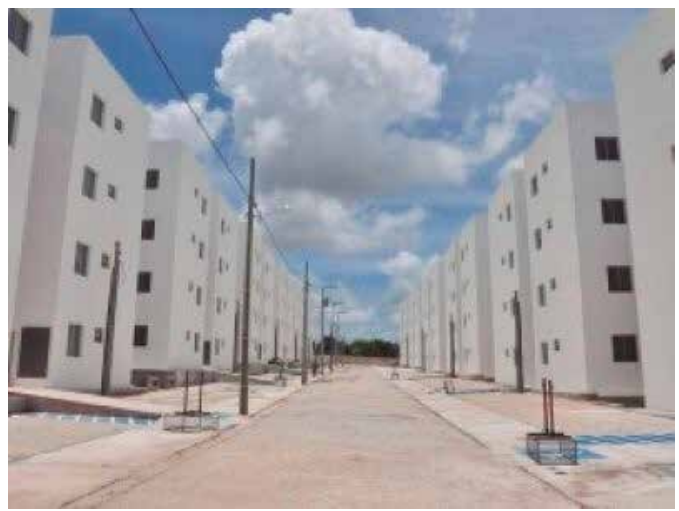

Disponível em: https:/www.pbagora.com.br/noticia/policial/moradores-do-vieira-diniz-denunciam-falta-de-seguranca/. Acesso em: 10 jun. 2019.

Os empreendimentos da Faixa 2 apresentaram qualidade construtiva e de acabamento superior, com unidades habitacionais com áreas um pouco maiores e áreas de uso comum mais completas (foto 2). Aqueles referentes à Faixa 3, por sua vez, diferenciam-se das demais faixas por apresentar, geralmente, edificaçóes verticalizadas com áreas de lazer e de uso comum com equipamentos mais diversificados como piscinas, quadras poliesportivas, garagens cobertas, entre outros (foto 3).

Foto 2 - Empreendimento PMCMV Faixa 2 (Res. Amália Gurgel), localizado no bairro Mangabeira, em João Pessoa - PB

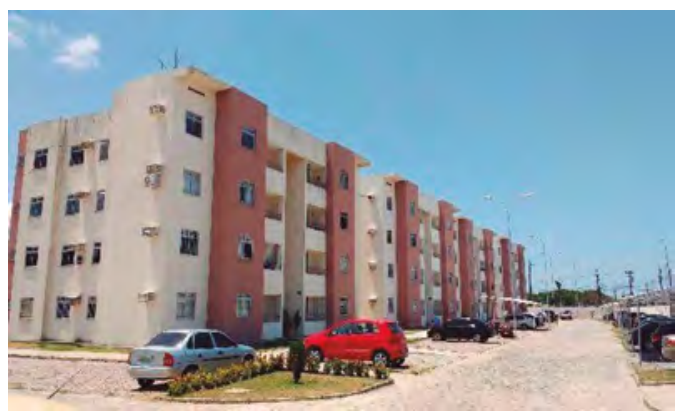

Disponível em: https://pb.mgfimoveis.com.br/aluguel-pb-joao-pessoa-apartamento-em-mangabeira-joao-pessoa-pb-perto-do-1120228. Acesso em: 10 jun. 2019. 
Foto 3 - Empreendimento PMCMV Faixa 3 (Res. Spazio di Napoli), localizado no bairro Tambauzinho, em João Pessoa - PB

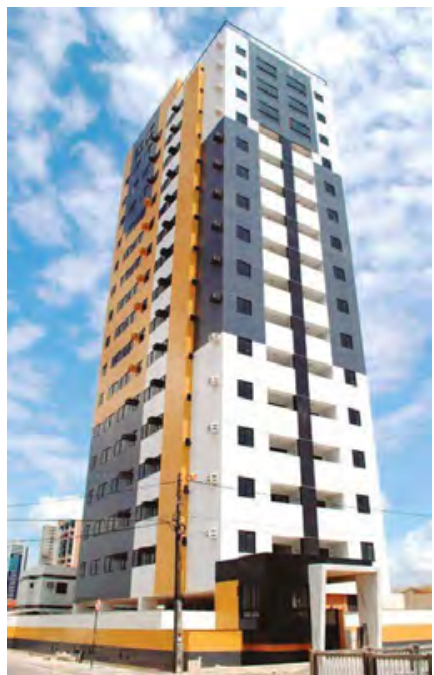

Disponível em: http://www.massai.com.br/novo/empreendimento/spazio-di-napoli-joao-pessoa/\#fotos. Acesso em: 10 jun. 2019.

Contudo, ressalta-se aqui que, em ambos os casos, as plantas dos apartamentos apresentaram, em sua maioria, ambientes com áreas mínimas permitidas, o que significa dizer que, apesar do preço do imóvel ser mais alto e da estrutura do empreendimento ser mais completa na Faixa 3, as unidades habitacionais foram projetadas seguindo um padrão de racionalização de espaços dos ambientes em detrimento do conforto e das necessidades reais dos seus futuros moradores.

O avanço da produção imobiliária sobre a periferia da cidade tem ocasionado a diversificação e complexificação desse espaço: antes lugar da autoconstrução e do loteamento irregular, ela agora é um espaço disputado e produzido pelos agentes imobiliários, pelos proprietários de terra e pelo Estado; não são construídos nela apenas edificações unifamiliares com estruturas precárias e sem infraestrutura; muitas vezes são instaladas infraestruturas básicas e são construídas outras tipologias, como casas geminadas, edifícios multifamiliares e condomínios horizontais com área de lazer, além de ser ainda comum encontrar terrenos ou glebas de grandes extensóes desocupados ou de uso agrícola ou pecuário (Martins, 2019). 
Assim, a periferia que, de acordo com Santos (1981), possuía conteúdo social específico e menor grau de participação na estruturação da cidade e um conteúdo social específico, passou a concentrar o capital no espaço ao atrair capital público e privado e reproduzi-lo com a intensificação da sua ocupação e a reprodução do espaço urbano.

Contudo, como afirmou Sposito (2004), as periferias urbanas nas cidades contemporâneas possuem novos conteúdos que não abrangem a superação da pobreza, da falta de integração e das más condiçóes de vida, mas a diversificação dos modos que esses espaços sáo produzidos e apropriados pela sociedade.

\section{Consideraçóes finais}

Apesar de proporcionar a regularização fundiária e a melhoria das condiçóes habitacionais de parte da população, os recentes programas do governo relacionados à produção do espaço urbano, de modo geral, reiteram a lógica da especulação fundiária e imobiliária, o que favorece financeiramente os proprietários de terra e promotores imobiliários e, também, ocasionam perdas para aqueles que involuntariamente passaram a habitar em áreas cada vez mais distantes dos locais de trabalho e de comércio e serviços.

De uma maneira geral, a ocupação intensa da periferia urbana de João Pessoa por meio da produção habitacional desencadeada pelo PMCMV expõe os avanços da produção imobiliária e da valorização fundiária e imobiliária sobre as áreas periféricas no início do século XXI.

Nesse processo emergem novas relaçóes socioespaciais e alteraçóes no processo de urbanização: a periferização não decorre mais do desenvolvimento e crescimento da indústria, mas da dinâmica econômica atual, que tem a reprodução do espaço urbano como elemento central para sua dinamização junto ao capital financeiro, reproduzindo e intensificando a segregação e a desigualdade na cidade. Como explicou Rufino (2016),

Os impactos da disseminação dessa lógica de produção sobre as periferias não se restringem aos proprietários, tende ainda a promover novas formas de desigualdades, à medida que dificulta a produção de habitação mais acessível e entrava o seu acesso por outros meios de produção, que permanecem a acontecer com maior precariedade. Essa contradição, levada à periferia, tende a extinguir as condiçóes de acesso à moradia dos mais empobrecidos na 
cidade. Nesse sentido, as desigualdades se impóem com maior força entre os mais empobrecidos e não beneficiados por essa lógica de disseminação da propriedade imobiliária (p. 231).

Ao verificar a disposição locacional das construções dos empreendimentos do PMCMV Faixa 1, percebe-se que as áreas dos conjuntos estáo predominantemente na zona sul da cidade e, em sua maioria, com distância entre 7,5 e $10 \mathrm{~km}$ do Centro principal da cidade. Implementados sob o discurso da moradia digna e da casa própria para a população de baixa renda, eles impóem a este grupo uma moradia com localização que não lhe garante o direito à cidade. Náo se trata apenas de garantir a habitação, mas também condições dignas de acesso a serviços - educação, saúde e lazer - e infraestrutura.

Diante do que foi colocado acima, o setor imobiliário brasileiro de fato passou a intensificar e a expandir territorialmente sua produçáo, interferindo diretamente nas realidades urbanas das cidades brasileiras. Entretanto, tais mudanças não foram capazes de solucionar os problemas urbanos existentes, inclusive em relação ao déficit habitacional existente.

Como ressaltou Maricato (2015), apesar dos investimentos do governo voltados para a habitação e para as infraestruturas urbanas nos últimos 30 anos, não foram alterados o controle sobre a ocupação e uso do solo nem os grupos sociais que os dominam e, deste modo, a situação de desigualdade nas cidades se intensificou, piorando a cada dia, desencadeando um momento denominado pela autora de "crise urbana".

\section{Referências}

BOLAFFI, Gabriel. "Habitação e urbanismo: o problema e o falso problema". In: MARI-

CATO, Ermínia (Org.). A produção capitalista da casa (e da cidade) no Brasil Industrial. 1. ed. São Paulo: Alfa-omega, 1979. pp. 37-70.

BONATES, Mariana Fialho. Ideologia da casa própria... sem casa própria: O programa de Arrendamento Residencial na cidade de João Pessoa-PB. (Dissertação). Natal: Universidade Federal do Rio Grande do Norte, 2007.

CORRÊA, Roberto Lobato. O Espaço Urbano. 4. ed. São Paulo: Ática, 2003. 96p.

IBGE. Regiôes de influência das cidades 2007. Disponível em: https://biblioteca.ibge.gov.br/ visualizacao/livros/liv40677.pdf. Acesso em: 05 dez. 2017.

KOWARICK, Lúcio. A Espoliação Urbana. 1. ed. Rio de Janeiro: Paz e Terra, 1979. 202p. 
LAVIERI, João Roberto e LAVIERI, Maria Beatriz Ferreira. Evolução urbana de João Pessoa - pós 60 . In: GONÇALVES, R. C. et al (Org.). A questão urbana na Paraíba. 1. ed. João Pessoa: Ed. Universitária/UFPB, 1999. 74p. pp. 39-66.

MAIA, Doralice Sátyro. Tempos lentos na cidade: Permanências e Transformaçóes dos costumes rurais em João Pessoa - PB. (Tese). São Paulo: Universidade de São Paulo, 2000.

. "A habitação popular e o processo de periferização e fragmentação urbana: uma análise sobre as cidades de João Pessoa-PB e Campina Grande-PB”. Geosul, Florianópolis, v. 29, n. 58, pp. 89-113, jul./dez. 2014.

MARICATO, Ermínia. O impasse da política urbana no Brasil. 3. ed. Petrópolis: Vozes, 2014. $186 \mathrm{p}$.

. Para entender a crise urbana. 1. ed. São Paulo: Expressão Popular, 2015. 112p.

MARTINS, Paula Dieb. O imobiliário e a reestruturaçáo urbana: a cidade de João Pessoa/PB no século XXI. (Tese). João Pessoa: Universidade Federal da Paraíba, 2019.

MELAZZO, Everaldo Santos. "Estratégias fundiárias e dinâmicas Imobiliárias do capital financeirizado no Brasil”. Mercator, Fortaleza, v. 12, n. especial 2, pp. 29-40, set. 2013.

OLIVEIRA, Luciano Agra de Oliveira. Uma contribuição aos estudos sobre a relação de transportes e crescimento urbano: $O$ caso de João Pessoa - PB. (Dissertação). João Pessoa: Universidade Federal da Paraíba, 2006.

REIS, Nestor Goulart. Notas sobre Urbanização Dispersa e Novas Formas de Tecido Urbano. 1. ed. São Paulo: Via das Artes, 2006. 201p.

ROLNIK, Raquel. Guerra dos lugares: a colonização da terra e da moradia na era das finanças. 1. ed. São Paulo: Boitempo, 2015. 423p.

RUFINO, Beatriz. "Transformação da periferia e novas formas de desigualdade nas metrópoles brasileiras: um olhar sobre as mudanças na produção habitacional”. Cadernos Metrópole, São Paulo, v. 18, n. 35, pp. 217-36, abr. 2016.

SANTOS, Milton. Manual de Geografia Urbana. 1. ed. São Paulo: Hucitec, 1981. 226p.

. Urbanizaçâo Brasileira. 5. ed. São Paulo: Editora da Universidade de São Paulo, 2008. 176p.

SANTOS, César Simoni. A Fronteira Urbana: Urbanização, industrialização e mercado imobiliário no Brasil. 1. ed. São Paulo: PPGH-USP/FAPESP/Annablume, 2015. 366p.

SHIMBO, Lúcia Zanin. Habitação social, Habitação de mercado: a confluência entre Estado, empresas construtoras e capital financeiro. 2010. 361f. (Tese). São Carlos: Universidade de São Paulo, 2010.

SIERRA, Pablo Arias. Periferias y nuevas ciudades: el problema del paisaje em los procesos de dispersión urbana. 1. ed. Sevilla: Universidad de Sevilla, 2004. 552p.

SOUZA, Marcelo Lopes de. ABC do Desenvolvimento Urbano. 5. ed. Rio de Janeiro: Bertrand Brasil, 2003. 192p.

SPÓSITO, Maria Encarnação Beltrão. O chão em pedaços: Urbanização, economia e cidades no Estado de São Paulo. (Tese). Presidente Prudente: Universidade Estadual Paulista, 2004. VILLAÇA, Flávio. Espaço intra-urbano no Brasil. 2. ed. São Paulo: Studio Nobel, 2001. 392p. 